\title{
Improving Consumer Satisfaction with Addiction Treatment: An Analysis of Alumni Preferences
}

\author{
Ruchi M. Sanghani and Alexander K. Moler \\ Recovery Brands, New York, NY 10003, USA \\ Correspondence should be addressed to Ruchi M. Sanghani; ruchi@rehabs.com
}

Received 11 June 2015; Revised 4 September 2015; Accepted 7 September 2015

Academic Editor: Elisardo Becona

Copyright ( 2015 R. M. Sanghani and A. K. Moler. This is an open access article distributed under the Creative Commons Attribution License, which permits unrestricted use, distribution, and reproduction in any medium, provided the original work is properly cited.

\begin{abstract}
Objective. The primary objective of this investigation is to determine which individual and aggregate factors of residential addiction treatment centers are most significant influencers of alumni satisfaction. Design. Survey targeted alumni of residential addiction treatment facilities. Alumni were queried through a survey, which utilized Likert-scale matrices and binary response options: 379 respondents met the completion threshold. Alumni rated amenities and individual and group counseling factors; additionally, respondents provided feedback on two satisfaction proxies: cost worthiness and future recommendations. Descriptive and relational analyses were conducted, with the latter utilizing logistic regression models. Results. Individual factors' scores of group counseling, and overall aggregate group counseling score, are most enthusiastically positive. Group counseling is also the most significant influencer of satisfaction. Other significant influencers of satisfaction are met expectations for individual counseling and psychiatric care offerings. Conclusions. While individual counseling and facility amenities should not be ignored, group counseling may be the most significant influencer of alumni satisfaction. Long-term outcomes are not single-faceted; however, treatment providers should be encouraged to invest in high-quality group counseling offerings in order to best satisfy, and thereby empower, clients.
\end{abstract}

\section{Introduction}

Consumer satisfaction is essential for any business [1]. Businesses offering goods and services to consumers often request feedback from former customers to assess strengths and weaknesses and to leverage positive feedback and testimonials as marketing materials. As these testimonials become more digitized and more public on sites like Yelp, Facebook, and Google+, businesses have a high stake in ensuring that their consumers are satisfied with the quality of service or goods they provide $[2,3]$.

In the healthcare space, patient satisfaction has been formally assessed for several years. The Hospital Consumer Assessment of Healthcare Providers and Systems (HCAHPS) initiative provides a survey tool to measure patients' perspectives and satisfaction within hospital systems [4]. The HCAHPS survey aims to produce standardized data on patients' perspectives on hospital care to allow for meaningful comparisons between hospitals based on consumer importance and publicly represent these findings to encourage transparency and incentivize hospital systems to improve their quality of care [4].

The HCAHPS initiative has identified 21 rating items that have been determined to affect patient perspectives on hospital care and has generated a 32-question survey that assesses quality of care from nurses and doctors, hospital environment, and experiences in the hospital. While this survey instrument is widely used in the hospital setting, an equivalent tool does not exist to evaluate satisfaction and perspectives in other areas of medicine and health, including addiction rehabilitation programs. Unique in its function, residential addiction treatment centers simultaneously operate as healthcare providers and hospitality managers, delivering medical and psychological support while offering accommodations, meals, and amenities in lieu of a clients' typical home environment.

In this exploratory study, we aim to determine which criteria are most significant to influencing overall alumni satisfaction with an inpatient drug or alcohol rehabilitation facility. Because the residential and intensive outpatient 
addiction rehabilitation industry functions at the crux of social science, medicine, and hospitality services, we hypothesize that alumni perceptions of facility amenities and perceived quality of individual therapies and group counseling will have significant influence on alumni satisfaction. We also hypothesize that the presence of subsequent relapse after discharge from a facility as a proxy measurement for success will negatively influence alumni satisfaction.

\section{Methods}

2.1. Survey Design. A survey was created using SurveyMonkey's online survey design platform to assess alumni feedback and satisfaction of a recent stay in an inpatient drug or alcohol rehabilitation facility [5]. The survey contains 45 questions with an equal mix of single choice and open-ended questions. The survey also includes three matrix questions for evaluation of facility features, individual therapy, and group counseling. This survey is hosted on Rehabs.com's website [6].

Respondents were asked to evaluate their facilities by the following criteria: the facility's amenities and individual and group counseling services. They were also asked to respond to demographic and personal questions regarding age of entry into treatment, method of payment, and motivation to enter treatment. Responses to the facility services questions were collected on a 5-Point Likert Scale. The evaluated aspects are as follows:

(i) amenities-accommodations, meals and nutrition, exercise options, leisure/extracurricular, holistic offerings (e.g., yoga and meditation), staff support, connectivity (Internet/phone use), visitor policy, and cleanliness;

(ii) individual counseling-counselor availability, counselor training/experience, counselor respect for patient's treatment preferences, flexibility to switch counselors, inclusion of holistic approaches, and inclusion of alternative/creative treatment approaches;

(iii) group counseling-quality of lead counselor, frequency of meetings, consistency of meetings, member empowerment/safety, and conflict resolution.

2.2. Sample Selection. The survey targets alumni of inpatient drug or alcohol rehabilitation facilities whose most recent enrollment occurred within the past ten years. Respondents were targeted through SurveyMonkey Audience, which is a service that provides survey takers with targeted, representative sample populations [5]. Additionally, respondents were asked a qualifying question, to ensure they met targeting requirements. Inclusion criteria for analyses include a minimum survey completion of $75 \%$ over the variables forming the aggregate scores (i.e., category components) and $100 \%$ over the remaining relevant variables. Survey data collected from August 25, 2014, to February 22, 2015, were included in these analyses.

2.3. Analytical Approach. Survey data were cleaned, recoded, and analyzed using Stata/IC 13.1 [7]. Of the 864 survey responses received, 485 responses did not fit the sample parameters for completeness and were removed from the database, resulting in a sample of 379 surveys. Recoding was required to convert the survey platform's default coding into a consistent format compatible with Stata's requirements. Full details regarding cleaning and coding (.log) are available at the reader's request.

Data were analyzed using a variety of logistic regression models, due to the outcome variables being dichotomous. For the purpose of these analyses, the dataset was declared as survey data, using Stata's svyset command. Each respondent served as a sampling unit. Linearized variance estimation was used. All of the following analyses utilized the appropriate svy command prefix, unless otherwise noted.

The likelihood of a respondent responding positively (i.e., answering "yes") to the binary questions "was treatment worth the cost?" and "would you recommend the facility to a friend or family member?" was assessed by examining the impact of the respondent's perception of the facility's offerings. To better evaluate this potential impact, the individual offerings in each category were condensed into three aggregate variables. Each aggregate variable was formed by finding the mean of the respective category component scores for each respondent.

All data were deidentified, and respondents provided consent for use of survey data in public reporting and research directly on the survey.

\section{Results}

Results from 379 surveys met inclusion criteria and were used for analyses. Two metrics were considered indicators of satisfaction with the facility attended: if treatment was worth the cost, and if the respondent would recommend this facility to a friend or family member who is seeking addiction treatment. These two metrics were considered indicators of satisfaction as recommendations and personal cost-benefit ratios are standard proxies for satisfaction in marketing practices, as well as in health service assessments [4, 8-14].

\subsection{Survey Population Profile and Facility Satisfaction}

3.1.1. Population Profile. Detailed information regarding demographic information can be found in Table 1. $66.05 \%$ $(n=249)$ of respondents entered inpatient addiction treatment between 40 and 59 years of age. Treatment was sought by individuals most frequently at their own behest $(62.33 \% n=235)$ and was most commonly paid for through private $(33.86 \% n=128)$ or government-provided $(18.25 \% n=69)$ insurance.

Cross tabulations were also conducted to view the intersection of these entrance factors. The most frequently occurring profile is an individual that entered treatment as a personal choice between the ages of 40 and 59 years. This profile fits $42.13 \%(n=158)$ of respondents. The second most frequently occurring profile is an individual that entered treatment as a personal choice, between the ages of 26 and 39 years; this profile fits $13.87 \%(n=52)$ of respondents. 
TABle 1: Population profile of 379 survey respondents.

\begin{tabular}{|c|c|c|c|}
\hline Demographic category & $\begin{array}{c}\text { Sample } \\
\text { size }\end{array}$ & Frequency & $\begin{array}{c}\text { Percent } \\
\text { distribution }\end{array}$ \\
\hline Age of entering treatment & 377 & & \\
\hline Under 18 & & 1 & 0.27 \\
\hline $18-25$ & & 20 & 5.31 \\
\hline $26-39$ & & 86 & 22.81 \\
\hline $40-59$ & & 249 & 66.05 \\
\hline $60+$ & & 21 & 5.57 \\
\hline Reason for entering treatment & 377 & & \\
\hline Family intervention & & 53 & 14.06 \\
\hline Court mandated & & 23 & 6.10 \\
\hline Doctor recommended & & 36 & 9.55 \\
\hline Personal choice & & 235 & 62.33 \\
\hline Other & & 30 & 7.96 \\
\hline Referral to facility & 379 & & \\
\hline Medical referral & & 87 & 22.96 \\
\hline Friend or family referral & & 118 & 31.13 \\
\hline Legal referral & & 16 & 4.22 \\
\hline Personal search & & 101 & 26.65 \\
\hline Other & & 57 & 15.04 \\
\hline Primary payment method & 378 & & \\
\hline Self-pay & & 60 & 15.87 \\
\hline Family or friend support & & 23 & 6.08 \\
\hline External financing (e.g., loan) & & 2 & 0.53 \\
\hline State or federal insurance & & 69 & 18.25 \\
\hline Private insurance & & 128 & 33.86 \\
\hline Combination of the above & & 49 & 12.96 \\
\hline Other & & 47 & 12.43 \\
\hline
\end{tabular}

3.1.2. Perception of Facilities. Likert-scale scores were calculated for each individual metric regarding amenities, individual counseling, and group counseling (Table 2). Amenities received an overall composite Likert-scale score of 3.99 ( $s d=0.97)$. Respondents scored four out of nine amenities factors highly (Likert-scale score > 4.00). With regard to individual counseling offerings, which received an overall score of 3.84 ( $s d=1.14)$, respondents highly rated counselor training and experience $(4.36 \mathrm{sd}=1.10)$, as well as their respect for the individual's treatment preferences $(4.25$ sd $=1.18)$. Respondents were less pleased with counselors' willingness to incorporate holistic approaches $(3.18 \mathrm{sd}=1.62)$. Group counseling offerings were given an overall score of 4.37 ( $s d=1.00)$. Each of the five factors of group counseling was given a score greater than 4.00 , with the frequency of group meetings receiving the highest Likert-scale score.

3.1.3. Was Treatment Worth the Cost? Four models were constructed using logistic regression to evaluate factors impacting an individual's notion of treatment being worth the cost. The results from these models are found in Table 3. The first model regresses the three summed aggregate offering scores regarding amenities (variable name = afacilityscore), individual counseling (acounsscore), and group counseling (agrpcounsscore) on the variable for "was treatment worth the cost?" (worcost). The second model regresses three "expectation" variables on worcost. These variables are "did the facility deliver the promised amount of counseling?" (promcouns); "did psychiatric care meet expectations?" (psyexpect); and "did marketing materials accurately portray the facility's offerings?" (market). The third model regresses the preceding six models on worcost. The fourth model adjusts model 1c, taking into account whether or not the respondent had relapsed. The results of each model are as follows:

(i) Model 1a-the aggregate mean group score is statistically significant, with a $p$ value of 0.022 . The group counseling score produced the highest degree of substantive significance; each point increase of the group counseling score corresponds with an increase in the odds of the respondent regarding their treatment as worth the cost by $126 \%$.

(ii) Model $1 b$-all three variables are statistically significant. Whether or not the facility provided the promised amount of counseling has the highest degree of substantive significance. Moving from "no" to "yes" on this variable corresponds to approximately a 37-fold increase in the odds of the respondent regarding his treatment as worth the cost.

(iii) Model $1 c$-combining the previous two models yields interesting results. Notably, when adjusting for offerings scores, the marketing materials accuracy becomes statistically insignificant. Additionally, "psychiatric care" is no longer significant to the 0.001 level; it also loses degrees of substantive significance. When taken together, this suggests that these variables are not the strongest predictive components. Promised amount of counseling and aggregate mean group counseling score remain statistically significant and increase in substantive significance.

(iv) Model $1 d$-model suggests that "relapse" is not a predictive component of whether or not the respondent considers their treatment as worth the cost, as "relapse" is not statistically significant. Furthermore, adjusting for relapse increases the substantive significance of aggregate mean group counseling score and "psychiatric expectations" score. Reproducing this model without the svy-estimation and conducting a Likelihood ratio test with 1c yield a statistically insignificant result, suggesting that the model is not an improvement over 1c.

3.1.4. Would You Recommend the Facility? Four models were constructed using logistic regression to determine potentially influential factors on alumni's willingness to recommend the facility where they received treatment, represented by the variable recff. The results from these models are found in Table 4. The first model regresses the aforementioned three aggregate mean offering scores (afacilityscore, acounsscore, and agrpcounsscore) on recff. The second model regresses the three aforementioned "expectation" variables (promcouns, 
TABLE 2: Mean values for respondent's ratings of facility offerings.

\begin{tabular}{|c|c|c|c|}
\hline Facility offering & Sample size & Mean & Standard deviation \\
\hline \multicolumn{4}{|l|}{ Amenity category } \\
\hline Accommodations & 378 & 4.23 & 1.03 \\
\hline Meals and nutrition & 368 & 4.39 & 1.01 \\
\hline Exercise options & 366 & 3.81 & 1.27 \\
\hline Leisure and extracurricular offerings & 259 & 3.80 & 1.27 \\
\hline Holistic offerings & 319 & 3.19 & 1.60 \\
\hline Staff support & 367 & 4.38 & 1.12 \\
\hline Connectivity & 338 & 3.48 & 1.49 \\
\hline Visitor policy & 355 & 3.98 & 1.31 \\
\hline Cleanliness & 366 & 4.46 & 1.01 \\
\hline \multicolumn{4}{|l|}{ Individual counseling category } \\
\hline Counselor availability & 364 & 3.95 & 1.34 \\
\hline Counselor training and experience & 375 & 4.36 & 1.10 \\
\hline Respect for patient's treatment preferences & 370 & 4.25 & 1.18 \\
\hline Flexibility to switch counselors & 299 & 3.58 & 1.54 \\
\hline Inclusion of holistic approaches & 308 & 3.18 & 1.62 \\
\hline Inclusion of alternative approaches & 324 & 3.34 & 1.58 \\
\hline \multicolumn{4}{|l|}{ Group counseling category } \\
\hline Quality of lead counselor & 378 & 4.38 & 1.08 \\
\hline Frequency of meetings & 378 & 4.48 & 0.99 \\
\hline Consistency of meetings & 378 & 4.42 & 1.03 \\
\hline Member empowerment and safety & 369 & 4.32 & 1.15 \\
\hline Conflict resolution & 371 & 4.23 & 1.19 \\
\hline \multicolumn{4}{|l|}{ Composite scores } \\
\hline Aggregate mean amenity score & 379 & 3.99 & 0.97 \\
\hline Aggregate mean individual counseling score & 379 & 3.84 & 1.14 \\
\hline Aggregate mean group counseling score & 379 & 4.37 & 1.00 \\
\hline
\end{tabular}

TABLE 3: Regression outcomes (worcost).

\begin{tabular}{|c|c|c|c|c|c|c|}
\hline Model & Dependent variables & Sample size & Odds ratio & $T$-statistic & $p$ value & $95 \%$ confidence interval \\
\hline \multirow{3}{*}{ la } & Aggregate mean amenity score & \multirow{3}{*}{379} & 1.73 & 1.15 & 0.252 & $0.68-4.43$ \\
\hline & Aggregate mean individual counseling score & & 1.55 & 1.35 & 0.177 & $0.82-2.94$ \\
\hline & Aggregate mean group counseling score & & 2.26 & 2.30 & 0.022 & $1.13-4.55$ \\
\hline \multirow{3}{*}{$1 b$} & Promised amount of counseling & \multirow{3}{*}{379} & 37.40 & 7.31 & $<0.001$ & $14.13-99.01$ \\
\hline & Psychiatric care meeting expectations & & 6.62 & 3.94 & $<0.001$ & $2.58-17.02$ \\
\hline & Marketing materials accuracy & & 3.13 & 2.28 & 0.023 & $1.17-8.41$ \\
\hline \multirow{6}{*}{$1 \mathrm{c}$} & Aggregate mean amenity score & \multirow{6}{*}{379} & 1.92 & 1.77 & 0.078 & $0.93-3.96$ \\
\hline & Aggregate mean individual counseling score & & 0.58 & -1.24 & 0.217 & $0.25-1.38$ \\
\hline & Aggregate mean group counseling score & & 2.65 & 2.29 & 0.023 & $1.15-6.13$ \\
\hline & Promised amount of counseling & & 45.01 & 5.61 & $<0.001$ & $11.86-170.78$ \\
\hline & Psychiatric care meeting expectations & & 3.41 & 2.32 & 0.021 & $1.20-9.64$ \\
\hline & Marketing materials accuracy & & 0.92 & -0.015 & 0.883 & $0.30-2.85$ \\
\hline \multirow{7}{*}{$1 d^{*}$} & Aggregate mean amenity score & \multirow{7}{*}{379} & 1.84 & 1.48 & 0.141 & $0.82-4.12$ \\
\hline & Aggregate mean individual counseling score & & 0.60 & -1.23 & 0.218 & $0.26-1.36$ \\
\hline & Aggregate mean group counseling score & & 2.69 & 2.22 & 0.027 & $1.12-6.47$ \\
\hline & Promised amount of counseling & & 44.88 & 5.59 & $<0.001$ & $11.77-171.08$ \\
\hline & Psychiatric care meeting expectations & & 3.51 & 2.23 & 0.026 & $1.16-10.65$ \\
\hline & Marketing materials accuracy & & 0.93 & -0.13 & 0.899 & $0.30-2.90$ \\
\hline & Respondent relapsed & & 1.20 & 0.32 & 0.749 & $0.392-3.68$ \\
\hline
\end{tabular}

${ }^{*}$ Likelihood ratio test $1 \mathrm{~d} / 1 \mathrm{c}$ not significant on non-svy $(p=0.760)$. 
TABLE 4: Regression outcomes (recff).

\begin{tabular}{|c|c|c|c|c|c|c|}
\hline Model & Dependent variables & Sample size & Odds ratio & $T$-statistic & $p$ value & 95\% confidence interval \\
\hline \multirow{3}{*}{$2 \mathrm{a}$} & Aggregate mean amenity score & \multirow{3}{*}{379} & 1.55 & 0.87 & 0.387 & $0.57-4.16$ \\
\hline & Aggregate mean individual counseling score & & 1.48 & 1.12 & 0.262 & $0.75-2.92$ \\
\hline & Aggregate mean group counseling score & & 2.56 & 2.79 & 0.006 & $1.32-4.97$ \\
\hline \multirow{3}{*}{$2 b$} & Promised amount of counseling & \multirow{3}{*}{379} & 7.61 & 3.80 & $<0.001$ & $2.67-21.76$ \\
\hline & Psychiatric care meeting expectations & & 4.89 & 3.50 & 0.001 & $2.00-11.91$ \\
\hline & Marketing materials accuracy & & 6.43 & 3.22 & 0.001 & $2.06-20.04$ \\
\hline \multirow{6}{*}{$2 \mathrm{c}$} & Aggregate mean amenity score & \multirow{6}{*}{379} & 1.20 & 0.43 & 0.669 & $0.52-2.80$ \\
\hline & Aggregate mean individual counseling score & & 1.05 & 0.11 & 0.909 & $0.48-2.30$ \\
\hline & Aggregate mean group counseling score & & 2.40 & 3.19 & 0.002 & $1.40-4.12$ \\
\hline & Promised amount of counseling & & 4.65 & 2.51 & 0.012 & $1.40-15.45$ \\
\hline & Psychiatric care meeting expectations & & 2.47 & 1.76 & 0.079 & $0.90-6.75$ \\
\hline & Marketing materials accuracy & & 2.52 & 1.52 & 0.130 & $0.76-8.38$ \\
\hline \multirow{7}{*}{$2 \mathrm{~d}^{*}$} & Aggregate mean amenity score & \multirow{7}{*}{379} & 1.36 & 0.68 & 0.495 & $0.56-3.32$ \\
\hline & Aggregate mean individual counseling score & & 0.94 & -0.16 & 0.876 & $0.40-2.17$ \\
\hline & Aggregate mean group counseling score & & 2.37 & 3.08 & 0.002 & $1.37-4.11$ \\
\hline & Promised amount of counseling & & 4.95 & 2.61 & 0.009 & $1.49-16.51$ \\
\hline & Psychiatric care meeting expectations & & 2.31 & 1.59 & 0.112 & $0.82-6.55$ \\
\hline & Marketing materials accuracy & & 2.48 & 1.48 & 0.141 & $0.74-8.30$ \\
\hline & Respondent relapsed & & 0.56 & -1.11 & 0.268 & $0.20-1.57$ \\
\hline
\end{tabular}

${ }^{*}$ Likelihood ratio test $1 \mathrm{~d} / \mathrm{lc}$ not significant on non-svy $(p=0.235)$.

psyexpect, and market) on recff. The third model regresses the preceding six variables on recff. The results of each model are as follows:

(i) Model 2a-each point increase of the group counseling score corresponds with an increase in the odds of the respondent recommending the facility by $256 \%$. The other two variables are not statistically significant.

(ii) Model $2 b$-all three included variables are significant to, at least, the 0.001 level. Of these variables, the most influential is the variable representing the promised amount of counseling; a respondent answering "yes" to this question corresponds to an increase in the odds that they would recommend the facility approximately $661 \%$.

(iii) Model 2c-by increasing model specification, a clearer picture of recff's predictors becomes apparent. For the group offering score and promised amount of counseling, the relative consistency in odds ratios and statistical significance across the two models suggests that these variables are influential factors in a facility receiving a positive alumni recommendation. This model also suggests that the respondent's perceptions of the facility's amenity offerings and individual counseling are not predictor variables, as these variables produced a statistically insignificant output over both models. Finally, when controlling for the offerings scores, the psychiatric expectation and accuracy of marketing materials variables are not statistically significant, suggesting that they may not be strong predictor variables, despite being statistically significant predictors in model $2 \mathrm{~b}$. (iv) Model 2d-“relapse" is not a significant predictor. Adjusting for relapse has minimal substantive effects on the significant predictor variables. As with 1d, reproducing this model without the svy-estimation and conducting a Likelihood ratio test with $2 \mathrm{c}$ yield a statistically insignificant result, suggesting the model is not an improvement over $2 \mathrm{c}$.

\section{Discussion}

The respondents' evaluations of their respective facility's offerings shed insight into the population's perception of inpatient treatment. The study results indicate trends in facility offerings and respondents' perceptions. In the aggregate, facilities are generally regarded as providing satisfactory to highly satisfactory offerings. This finding is consistent with reviews across other industries, where the literature has shown that the general reviews tend to have a negative skew distribution [15]. Alumni most highly rated group counseling. Alumni reception towards facilities' amenities and individual counseling is generally positive, albeit to a less enthusiastic degree compared to group counseling. Facilities' individual counseling offerings were the least enthusiastically received, particularly in regard to the facilities' inclusion of holistic, alternative, and creative approaches. This dissatisfaction with holistic offerings is also present in the amenities category, indicating that such an attitude is pervasive and present in the respondents' overall perception of the facility.

These analyses demonstrate important factors that may influence alumni satisfaction. Models $1 \mathrm{a}-\mathrm{d}$ aim to determine the most substantial predictors of satisfaction with the financial value provided by treatment. These models 
suggest that high-quality group counseling, as well as meeting or exceeding expectations for the amount of counseling received, is the most substantial and substantively significant predictors of satisfaction relating to cost worthiness. Additional statistically significant predictors of satisfaction for this metric are psychiatric care meeting expectations and, to a lesser extent, individual counseling offerings. Models $2 \mathrm{a}-\mathrm{d}$ suggest key factors in alumni's willingness to recommend a facility to their friends or family members. Specifically, the results suggest that the respondent's perceptions of their group counseling experiences, whether or not the facility delivered its promised amount of counseling and, to a slightly lesser extent, whether psychiatric care meets expectations, are instrumental in alumni's decision to recommend their facility.

The selected outcome variables and their responses are proxy measures of consumer satisfaction with treatment facilities' services. Evaluating the models related to these two variables simultaneously highlights strong and consistent potential predictors of consumer satisfaction with treatment facilities' services. For both outcomes, and across each relevant model, the aggregate group counseling score and whether the facility kept its promises regarding individual counseling are statistically significant predictors of a respondent's (i.e., consumer's) satisfaction with his or her treatment. This consistency across outcomes and models suggests the presence of predictive power for these two aspects of treatment services. To a lesser extent, this consistency is also observed for variables representing individual counseling and whether the facility delivered the expected psychiatric care.

These results are strengthened by the failure to confirm the second hypothesis; adjusted for the other selected variables, whether the respondent had relapsed or not was not a statistically significant predictor of alumni satisfaction. Furthermore, its inclusion with these other potential predictor variables may not serve as necessary or beneficial specification. Facilities should not approach their clients' satisfaction with fatalistic uncertainty that the client's postdischarge actions will solely create a negative retrospective perception of treatment; rather, facilities should recognize that their actions can directly and primarily impact satisfaction, regardless of long-term client outcomes.

Improving offerings and, in turn, improving satisfaction can aid recovery. It is well documented in the literature that higher patient satisfaction scores correlate well with medical treatment adherence [16, 17]. For those struggling with addiction, adherence to a treatment plan is vital to recovery. Facilities should aim to provide the most satisfactory service to promote treatment adherence. While individual counseling and amenity offerings certainly should not be ignored, high-quality group counseling should be supported and promoted to enhance clients' treatment experience. Improving satisfaction with group counseling offerings has the highest likelihood of improving overall consumer satisfaction, which in turn is likely to support greater adherence to a recovery plan-a goal that should guide facilities' operations. Through incorporating empirical research into operational policy, facilities can ensure that changes they make have a demonstrable impact.
The importance placed on group counseling offerings should not solely be viewed through the lens of predicting consumer satisfaction, as broader implications for the treatment space exist. In addition to the aggregate group counseling score being the most consistent substantively and statistically significant predictor, each of its components, collectively, had the highest mean perception scores of the three aggregate categories. Viewed together, these findings suggest that consumers are most enthusiastic and receptive to group counseling offerings.

Investigations into the role of social support on treatment adherence within the addiction space, and across several other health and wellness industries, have demonstrated moderate to significant improvements in adherence [18-21]. Just as satisfaction can improve adherence, adherence-and subsequently resulting treatment "success"-can positively influence retrospective perceived satisfaction, thus beginning a cyclical pattern for satisfaction and treatment adherence $[22,23]$. For treatment providers, the construction of social support during treatment may build the foundation for successful and satisfactory long-term recovery. Future research should aim to determine how group therapies improve satisfaction scores and treatment adherence to encourage clients' recovery.

This study includes the limitation that only two metrics were chosen as proxies for satisfaction. While cost worthiness and recommendations are significant proxies for satisfaction, other proxies may also exist. Subsequent investigations may include the use of other metrics indicating satisfaction to test our findings. Respondent recruitment utilized a self-selection method, which could contribute to selection bias within the study's sample population. Specifically, as the survey was hosted online, respondent demographics will reflect general Internet user demographics, which may not be reflective of the general population. Precise demographics for both the general population of rehabilitation alumni are unavailable, limiting the ability to determine sample representativeness. Additionally, as reviews tend to skew positive, the potential predictor factors discussed below may not be generalizable for unenthusiastic alumni. Selection bias will be further addressed as future studies move away from exploratory efforts.

\section{Conclusions}

Through producing multiple models in regard to two outcome variables, our results highlight potentially key predictors of alumni's satisfaction with their treatment experience. Across both outcome variables, alumni's perceptions of the facility's group offerings and the facility keeping its promises regarding individual counseling are statistically and substantively significant. The alumni's perceptions of the facility's marketing materials' accuracy and whether the facility delivered the expected psychiatric care are also statistically and substantively significant, but inconsistently so. Satisfaction with treatment may be correlated with increased treatment adherence and subsequent long-term success in recovery. The addiction treatment space would benefit greatly from further research into the impact of these predictors, 
through refining of the aggregate component measurements, as well as evaluating the impact of components themselves, to gain a more clear understanding of predictors of consumer satisfaction and thus a better understanding of the treatment space.

\section{Consent}

All respondents provided consent for their deidentified data to be used in this study and submitted for publication.

\section{Disclosure}

Recovery Brands, LLC, is an independent subsidiary of American Addiction Centers, a for-profit entity operating in the addiction space. The authors have read and confirmed their agreement with the ICMJE authorship and conflict of interests criteria.

\section{Conflict of Interests}

The authors declare that there is no conflict of interests regarding the publication of this paper.

\section{Authors' Contribution}

This project was jointly conceived, designed, and executed by Ruchi M. Sanghani and Alexander K. Moler. Both Ruchi M. Sanghani and Alexander K. Moler agree with the paper results and conclusions. Both authors reviewed and approved the final paper.

\section{Acknowledgments}

The authors wish to acknowledge Jeff Smith, Abhilash Patel, and Melanie Haber for their support of this publication, as well as Alexandra Carlin and Travis Leleu for their editorial contributions. This study was financially supported by Recovery Brands, LLC.

\section{References}

[1] P.-Y. Chen, S.-Y. Wu, and J. Yoon, "The impact of online recommendations and consumer feedback on sales," in Proceedings of the International Conference on Information Systems (ICIS '04), Paper 58, Washington, DC, USA, December 2004, http://aisel.aisnet.org/icis2004/58.

[2] G. Shaw, "Reviews are in: keep tabs on online reputation, experts say," The Hearing Journal, vol. 67, no. 10, pp. 14-18, 2014.

[3] Study: $81 \%$ research online before making big purchases, Retailing Today, 2013, http://www.retailingtoday.com/article/study81-research-online-making-big-purchases.

[4] Centers for Medicare \& Medicaid Services, HCAHPS Fact Sheet (CAHPS Hospital Survey): April 2015, Hospital Consumer Assessment of Healthcare Providers and Systems, Centers for Medicare \& Medicaid Services, Baltimore, Md, USA, 2015, http://www.hcahpsonline.org/Files/HCAHPS_Fact_Sheet_April_ 2015.pdf.
[5] SurveyMonkey, Palo Alto, Calif, USA, http://www.surveymonkey.com.

[6] Facility Reviews, Rehabs.com, San Diego, Calif, USA, August 2014, http://www.rehabs.com/reviews/start/.

[7] Stata Statistical Software: Release 13, StataCorp LP, College Station, Tex, USA, 1999.

[8] A. Chaudhuri and M. B. Holbrook, "The chain of effects from brand trust and brand affect to brand performance: the role of brand loyalty," Journal of Marketing, vol. 65, no. 2, pp. 81-93, 2001.

[9] R. Hallowell, "The relationships of customer satisfaction, customer loyalty, and profitability: an empirical study," International Journal of Service Industry Management, vol. 7, no. 4, pp. 27-42, 1996.

[10] E. Sivadas and J. L. Baker-Prewitt, "An examination of the relationship between service quality, customer satisfaction, and store loyalty," International Journal of Retail \& Distribution Management, vol. 28, no. 2, pp. 73-82, 2000.

[11] J. Lu, "A model for evaluating E-commerce based on cost/ benefit and customer satisfaction," Information Systems Frontiers, vol. 5, no. 3, pp. 265-277, 2003.

[12] M. Lee and L. F. Cunningham, "A cost/benefit approach to understanding service loyalty," Journal of Services Marketing, vol. 15, no. 2, pp. 113-130, 2001.

[13] Z. Yang and R. T. Peterson, "Customer perceived value, satisfaction, and loyalty: the role of switching costs," Psychology \& Marketing, vol. 21, no. 10, pp. 799-822, 2004.

[14] G. Ciotti, The Ultimate Guide to Measuring Customer Satisfaction, Help Scout, 2013, http://www.helpscout.net/blog/customer-satisfaction.

[15] B. Kadry, L. F. Chu, B. Kadry, D. Gammas, and A. MacArio, "Analysis of 4999 online physician ratings indicates that most patients give physicians a favorable rating," Journal of Medical Internet Research, vol. 13, no. 4, article e95, 2011.

[16] K. Aljumah, A. A. Hassali, and S. AlQhatani, "Examining the relationship between adherence and satisfaction with antidepressant treatment," Neuropsychiatric Disease and Treatment, vol. 10, pp. 1433-1438, 2014.

[17] A. Di Paula, R. Long, and D. E. Wiener, "Are your patients satisfied?" Marketing Health Services, vol. 22, no. 3, pp. 28-32, 2002.

[18] P. L. Dobkin, M. De Civita, A. Paraherakis, and K. Gill, "The role of functional social support in treatment retention and outcomes among outpatient adult substance abusers," Addiction, vol. 97, no. 3, pp. 347-356, 2002.

[19] M. R. DiMatteo, "Social support and patient adherence to medical treatment: a meta-analysis," Health Psychology, vol. 23, no. 2, pp. 207-218, 2004.

[20] D. Richards, D. J. Bartlett, K. Wong, J. Malouff, and R. R. Grunstein, "Increased adherence to CPAP with a group cognitive behavioral treatment intervention: a randomized trial," Sleep, vol. 30, no. 5, pp. 635-640, 2007.

[21] A. Steptoe, J. Wardle, T. M. Pollard, L. Canaan, and G. J. Davies, "Stress, social support and health-related behavior: a study of smoking, alcohol consumption and physical exercise," Journal of Psychosomatic Research, vol. 41, no. 2, pp. 171-180, 1996.

[22] R. L. Kane, M. Maciejewski, and M. Finch, "The relationship of patient satisfaction with care and clinical outcomes," Medical Care, vol. 35, no. 7, pp. 714-730, 1997.

[23] J. L. Jackson, J. Chamberlin, and K. Kroenke, "Predictors of patient satisfaction," Social Science \& Medicine, vol. 52, no. 4, pp. 609-620, 2001. 


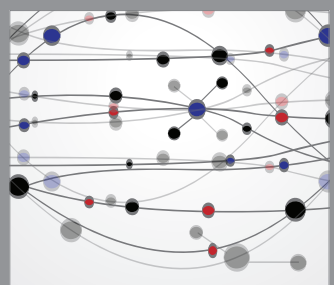

The Scientific World Journal
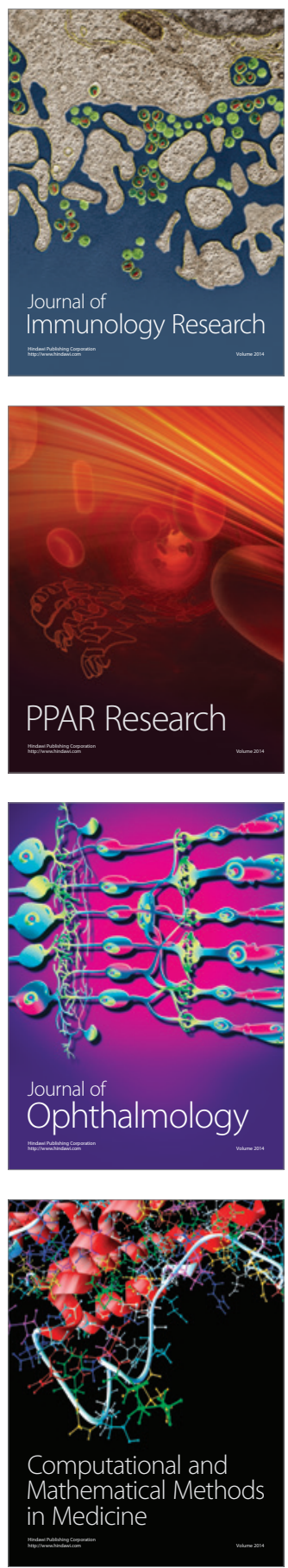

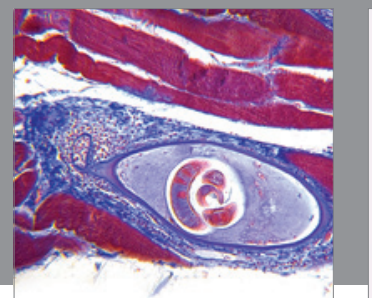

Gastroenterology

Research and Practice
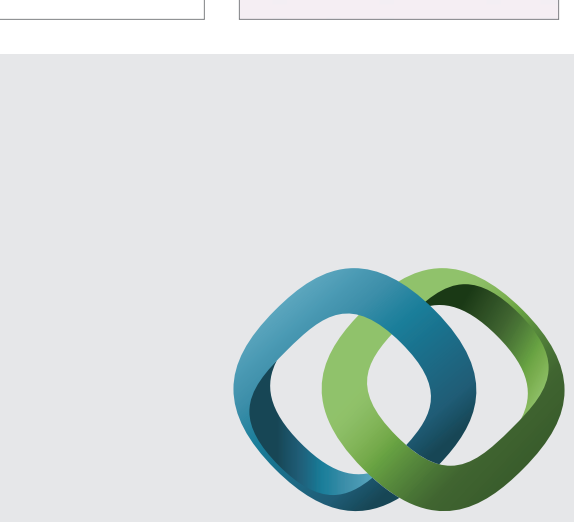

\section{Hindawi}

Submit your manuscripts at

http://www.hindawi.com
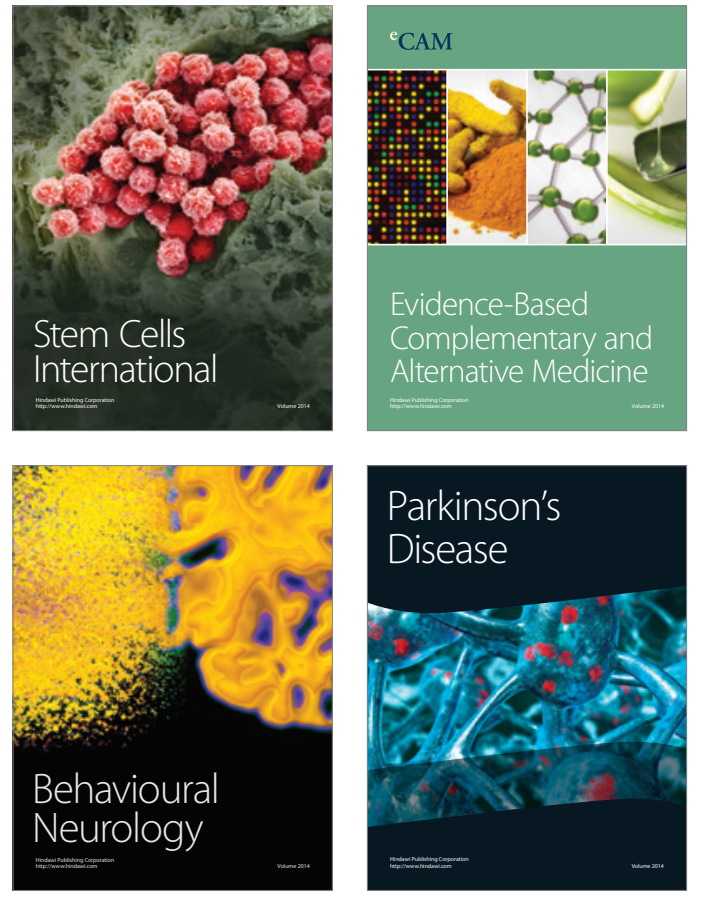
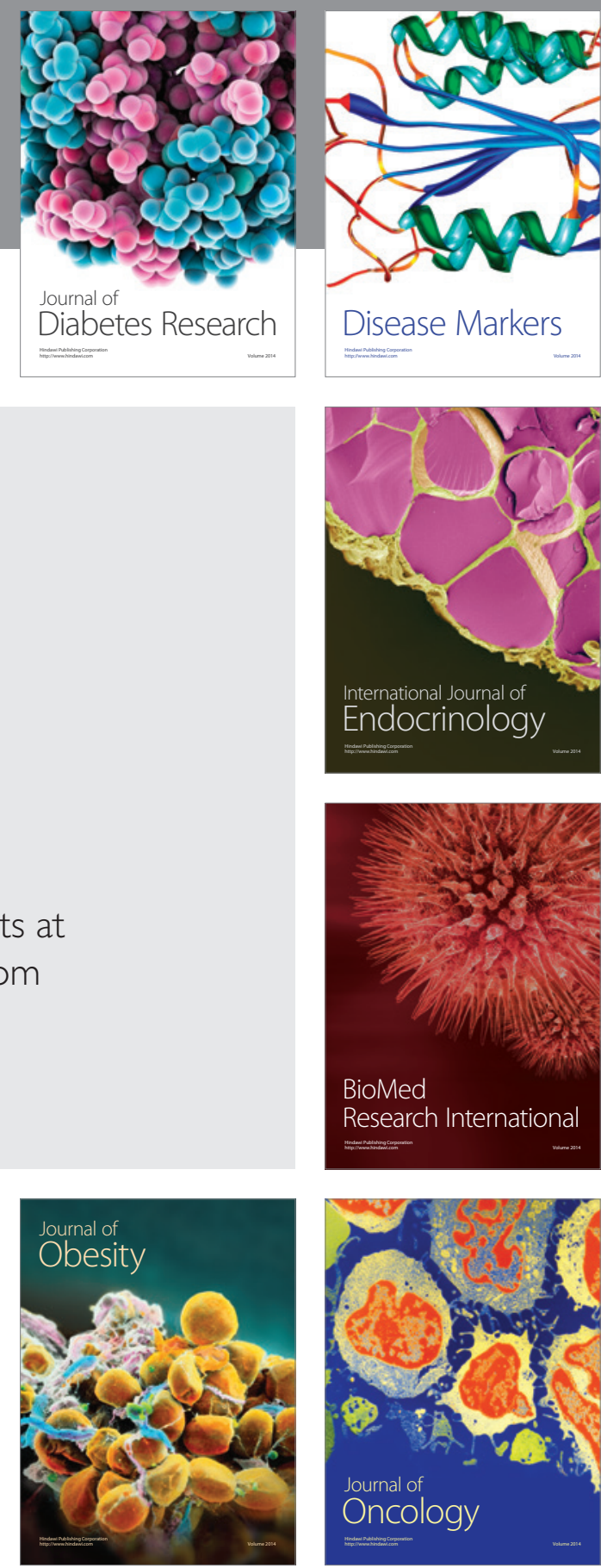

Disease Markers
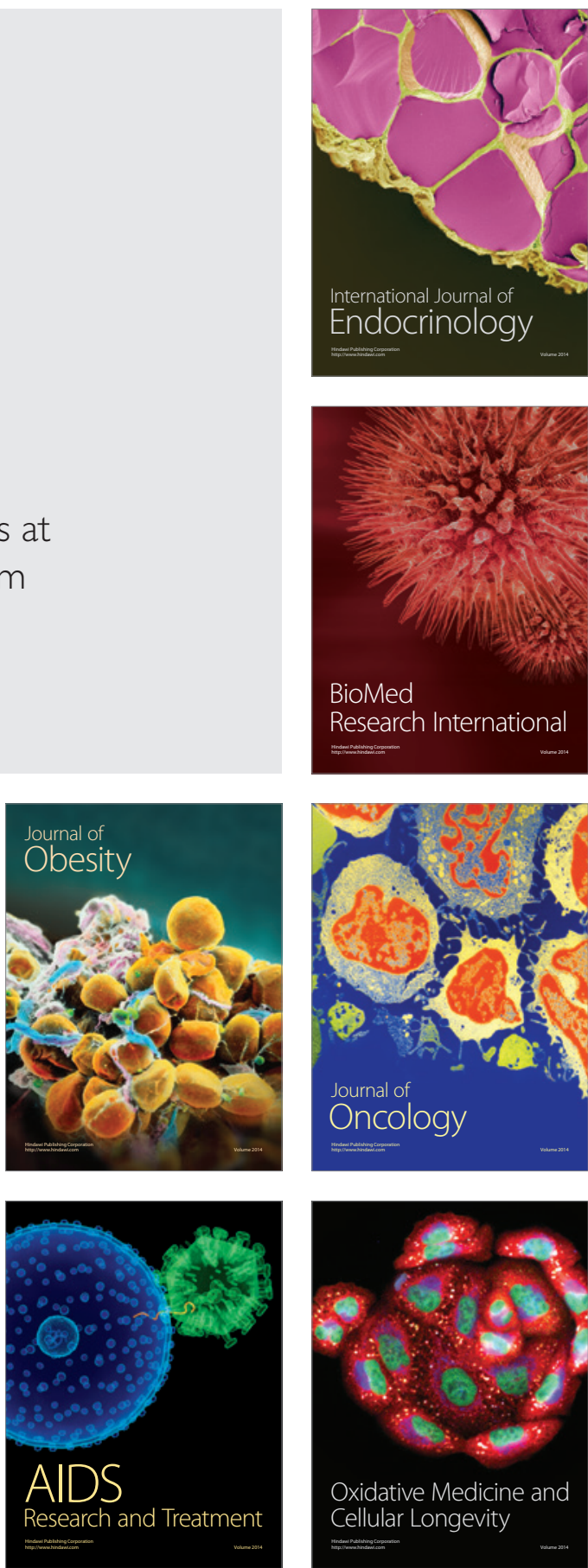